\author{
Military Technical College \\ Kobry El-Kobbah, \\ Cairo, Egypt
}

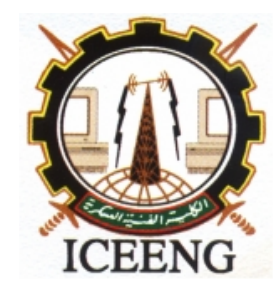

\section{$8^{\text {th }}$ International Conference on Electrical Engineering \\ ICEENG 2012}

\title{
Investigating the impact of smart grids' contributions in developing countries
}

\author{
By
}

\author{
Walid El-Khattam*
}

Marwa Mostafa**

\begin{abstract}
:
The ability to improve safety and efficiency of the electric networks, making better use of existing assets, enhancing reliability and power quality, reducing dependence on imported energy, and minimizing costly environmental impacts are the main forces that have substantial economic value on the electricity industry. Most of the time, investment in generation, transmission, and distribution networks to achieve such benefits places a burden on developing countries' economies, which can be relieved by Smart Grid (SG) concepts implementation. SG will intelligently integrate the actions of all users connected to it; generators, grids, and consumers in order to efficiently deliver sustainable, economic, secure electricity supplies, provide self-healing, and take the full advantage of new technologies. This paper aims to assess the SG applications on the generation, transmission, distribution levels, and up to consumer sides in developed as well as developing countries. The main SG features are evaluated based on the available technologies and their span. The SG benefits that would reflect on utilities particularly aiming at integrating large amounts of Renewable Energy Sources (RES) into their grids and implementing distribution management, and consumers are presented. Moreover, a roadmap needed to achieve the mentioned SG application is proposed and discussed. Finally, the proposed recommendation and conclusions for the impact of SG on developing countries are illustrated.
\end{abstract}

\section{Keywords:}

Demand side management, smart grids, and renewable energy sources

* Electrical Power and Machines Department, Faculty of Engineering, Ain Shams University, Cairo, Egypt

** The Egyptian Electric Utility and Consumer Protection Regulatory Agency (EgyptERA), Cairo, Egypt 


\section{Introduction:}

SG concepts implementation is expected to fulfill the electric industry (utilities, manufacturers, investors, and researchers), consumers, and society need and relieve thier ambiguous concerns. From the utilities' perspective, deployment of SG technologies can successfully contribute in addressing concerns with new generation capacities and grids' infrastructure upgrade. In most countries, the rapid increase in electricity demand has led to an essential need for new generation capacities. At the same time, the reliance on fossil fuel for generating electricity has been affected by the unstable fuel prices and other environmental concerns. Therefore, many countries have increased their interest in integrating Renewable Energy Sources (RES) into their grids and further spreading the efficient cogeneration applications. Furthermore, most transmission and distribution grids undergo aging and vulnerability in many respects which require huge investments in order to improve their conditions.

Moreover, SG deployment could gain more potency as its value becomes clearer to all stakeholders, especially to residential consumers. Residential consumers are the key drivers for any country's economy as well as the strongest political constituency. Therefore it is vital that they clearly understand the benefits of SG by comprehensively tackling any concerns they might have regarding its implementation. Otherwise, they will lack the interest and motivation to support the SG transition process, or might become an obstacle to its development. In this context, many countries develop strategies targeting Demand Side Management (DSM) for better usage of energy resources including Load Management (LM), Demand Response (DR), and Energy Efficiency (EE) programs. These strategies address methods on how smart domestic appliances can contribute to LM in future energy systems.

This paper investigates the positive impacts that the SG implementation can contribute for developing countries. In Section 2, the SG achievements in developed countries are illustrated versus the required needs in SG applications in developing countries. The SG features are reported in Section 3 to correlate them to the available SG technologies and their span of contribution. In Section 4, the SG aimed benefits from the utilities', consumers', and societies' perspectives and their applications are discussed. In Section 5 , the roadmap towards SG implementation is presented. The proposed roadmap to achieve the SG benefits in developing countries is tackled. Finally, conclusions and recommendations are reported.

\section{SG in Developed Countries vs. Developing Countries:}

The drivers and challenges (both technical and non-technical) for SG development vary 
by geographic location. Figure 1 shows that in developed countries the drive is to integrate larger amounts of RES, while in developing countries the drive is peak load reduction and electric supply shortage concerns.

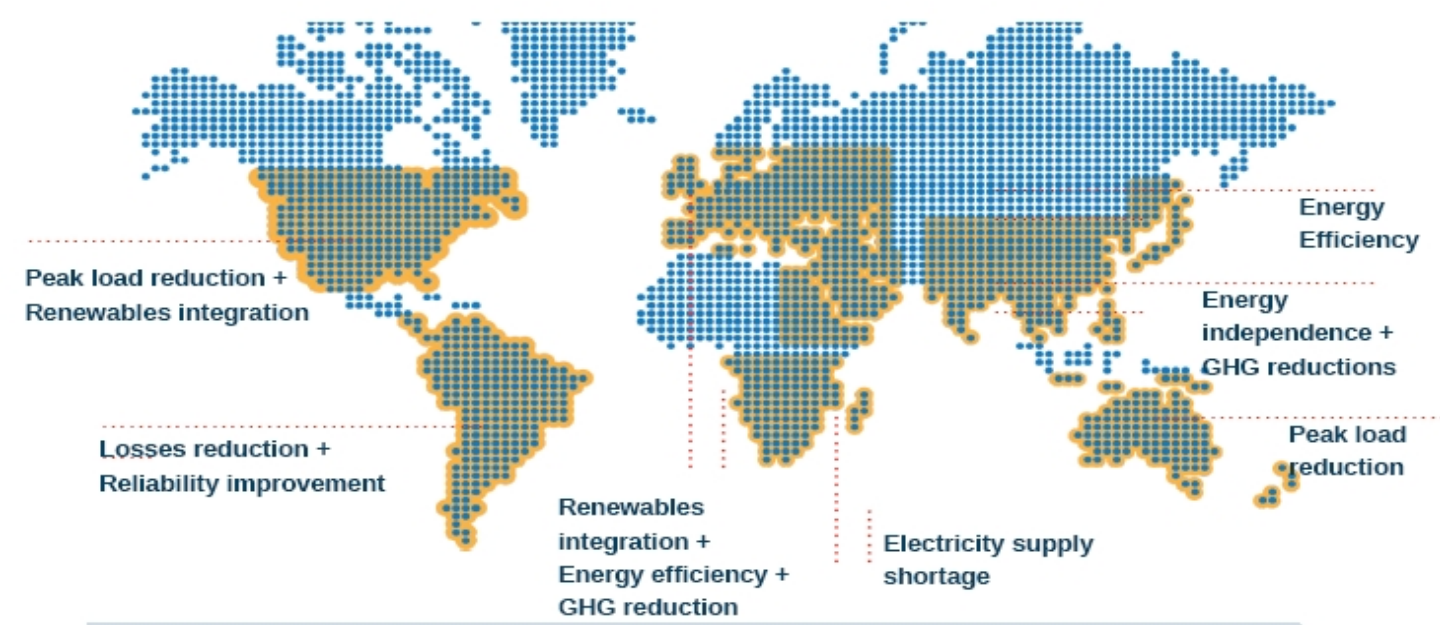

Figure (1): The worldwide SG development drivers by geographical locations [1]

\section{Developed countries:}

North America (US)

In the U.S., there are key supporting drives for grid automation, including more than $\$ 9$ billion in current grant/privately-funded projects, which is the highest per-capita energy use in the world. In addition, strong interests from private sector funding and innovation, as well as integrated utilities are also considered key drives. On the other hand, the lack of a national energy policy which limits overall direction and certainty, incomplete and fully-approved industry standards, vulnerable regulations for cost recovery, increasing concerns and mistrust by consumers over cyber security are considered the main constraints facing the SG spread in US [1].

\section{Europe}

The European Union (EU) has implemented policies to achieve the 20/20/20 objective (20\% RE, $20 \%$ improvement in EE, and 20\% reduction of GHG emissions). Furthermore, the Third Energy Package policy seeks to automate $80 \%$ of the electric meters in Europe to be "smart" by 2020. On the other hand, the decentralized nature of utilities' markets leads to greater complexity for achieving SG benefits and necessitates considerable sharing of technology demonstration programs for the benefit of all market participants [1].

Examples of EU SG achievements are as follows [2]:

1) In 2011, the Italian regulator has awarded eight tariff-based funded projects on medium voltage distribution systems, to demonstrate advanced network 
management and automation solutions essential to integrate Distributed Generation (DG). In addition, a grant over EUR 200 million for SGs demonstration and network modernization in Southern Italian regions has been awarded.

2) In 2008, the Spanish government obliged distribution companies to replace existing meters with new SMs with no additional cost to the customer. Two utilities targeted deployment of automated meter management (AMM) to more than 23 million customers on the low voltage network from 2010 to 2015.

3) In 2009, the Australian government announced AUD 100 million 'Smart Grid, Smart City' initiative to serve a commercial-scale SG demonstration project. Additional efforts in the area of RE deployments are resulting in further studies on SGs.

4) In the UK, the energy regulator (OFGEM) has an initiative called the "Registered Power Zone" that motivates distributors to develop and implement innovative solutions to connect DGs to the grid.

5) In France, the electricity distribution operator (ERDF) is deploying 300,000 SMs in a pilot project based on an advanced communication protocol. If this pilot project proves to be successful, ERDF will replace all of its 35 million meters with SMs from 2012 to 2016.

\section{Asia Pacific (APAC)}

This region is just getting started in their deployment of SG. They have a strong potential to rapidly reach large scale SG implementation, and thus potentially exceeding any other global region. Their drive is the major funding to stimulate SG progress in China, Japan, Thailand, Singapore, and South Korea. Some demonstration projects aim to correlate intelligent grid technologies, SMs and broadband telecommunications with economies of scale driven by the world's largest utilities. Another key driver is the incorporation of numerous DGs as it has the world's largest natural gas reserves. However, APAC faces many challenges, including strong economic growth that concentrates on investments in power supply and grid expansion, and GHG reductions [1].

Examples of the APAC SG achievements are as follows [2]:

1) In China, the government has developed a large, long-term stimulus plan to invest in power grids including a substantial investment in SGs to reduce energy consumption, increase network efficiency and control electricity generation from RES. China's State Grid Corporation set plans in 2010 for a pilot SG program that outlines the deployment process up to 2030.

2) In Japan, the Federation of Electric Power Companies of Japan is developing an SG plan that includes solar power generation by 2020 with governmental investment of over 100 million USD. In addition, the government has announced a 
national SM initiative and large utilities have announced SG programs.

3) In South Korea, the government has started a 65 million USD pilot program consisting of a fully integrated SG system for 6,000 households, wind farms and four distribution lines. In addition, Korea has announced plans to implement SGs by 2030 .

\section{Developing countries:}

\section{South America}

The key assets supporting SG development include a strong need to improve reliability and decrease system losses, strong economic growth that supports system expansion, and finally significant interest in learning from other countries' experience before launching their own initiatives. On the other hand, the barriers are low per-capita energy consumption that can decrease consumer interest and benefits, relatively few ongoing pilot projects or demonstrations, vulnerable regulations for cost recovery. Moreover, capital investment is mostly directed towards grid expansion in some rural areas, where there is no access to the power grid [1].

In Brazil which is leading in SG deployment in South America, several utilities are managing SG pilot projects such as deploying smart meters (SMs) and securing the grid against theft in order to reduce losses. In addition, an SG business plan using the existing fiber-optic network is being developed [2].

\section{Africa}

Africa possesses rich resources which can satisfy its energy requirements or even more. This includes natural gas, oil and coal reserves. Also, Africa is quiet rich with hydro which is concentrated mainly on the Congo, Nile, Niger, Volta and Zambezi rivers, as well as other RESs. However, as of 2006, less than $15 \%$ of Africa's population had access to electricity that is also unreliable. It also suffers from limited electricity infrastructures, and regular blackouts as a result of power shortages. These conditions are the results of a lack of long-term planning, insufficient investment, poor maintenance, and the inefficiency of existing power utilities. Therefore, new generation capacities are needed to increase electricity access. This would require numerous investments to cover capital expenditure and O\&M. Being rich with RES, RE is considered a key option to cover the lack of power without depending on fossil fuel price fluctuations [3]. These available resources can be explored and used by the implementation of SG applications to overcome existing electricity availability and affordability obstacles.

Only South Africa is considered to be the leading country in SG implementation in the continent. In 2009, South Africa got into a pilot project to increase consumer awareness about energy efficiency. The pilot project was part of a program to assess the impact of 
new load limiting technology in controlling residential demand. An SG networks were installed in some chosen areas based on electricity network infrastructure rather than geographic location. Customers living in these areas were call upon to collect an electricity demand display instrument of no cost. The display instrument displays the real-time demand of the different electrical appliances in the household. This system can also be used to limit the supply to contributing households if there is a constraint on the grid. This pilot project proved success in using the display device, and consumers gained better awareness of electricity consumption. They believed they can save on electricity by using the display device. This has encouraged the roll-out of the display device nationally. Later on, other towns were also approached, and customers in specific pilot sites joined the LM Pilot during 2010 and 2011. The technical lessons learnt during these periods resulted in upgrading other load limiting systems and the display devices, which are currently being carried out [2].

On the other hand Egypt is planning to implement small scale SG pilot projects that focus only on SM applications.

It has to be mentioned that based on the previous discussion, the development of SG applications has to be started as soon as possible in developing countries to gain the benefits of SG applications. Many experiences and lessons can be considered from developed countries' progress which can expedite the SG transition process in developing countries.

\section{SG Features, Technologies, and Spans:}

SGs embrace major principal characteristics that align the route towards achieving the required benefits anticipated by different stakeholders, mainly utilities and consumers, as follows:

1) From the utilities' perspectives, it accommodates diverse resources with "plug-andplay" connections for generation and storage options. Also, it enables new products, services, and markets through the grid's open-access market, reduces transmission, optimizes asset utilization, and allows efficient operation and better functionality at minimum cost guide operations. Moreover, it allows efficient grid maintenance programs resulting in less equipment failures and safer operations. In addition, it anticipates and responds to system disturbances through selfassessments to detect, analyze, respond to, and as needed, restore grid components or network sections (self-healing).

2) From the consumer's perspective, it enables active contribution by consumers aiming to reduce the cost of delivered electricity and improves public safety as it can prevent/ withstand physical or cyber-attack [4]. 
SG benefits will result in enhancements in the following basic areas [4]:

- Reliability; by decreasing chances and upshots of blackouts as well as reducing the cost of interruptions and power quality disturbances

- Economics; by keeping low electricity prices, reducing electricity prices paid by consumers as compared to the traditional grid, creating new jobs, and stimulating the gross domestic product.

- Efficiency; by reducing generation, transmission, and distribution costs.

- Environmental; by enabling a larger integration of RES and improving efficiency of generation, transmission, distribution, and consumption

- Security; by decreasing chances and impacts of human attacks and natural disasters

- Safety; by decreasing injuries resulting from grid-related accidents.

The deployment of the proper technologies will improve how SG is planned, designed, operated, and maintained. The following technologies are generally considered when an SG implementation plan is developed:

- Advanced Metering Infrastructure (AMI)

- Customer Side Systems (CS)

- Demand Response (DR)

- Distribution Management System/Distribution Automation (DMS)

- Transmission Enhancement Applications (TA)

- Asset/System Optimization (AO)

- Distributed Energy Resources (DER)

- Information and Communications Integration (ICT)

Based on the targeted area for implementing SG, specific technological solutions shall contribute to achieve this target as shown in Table 1.

Table (1): SG key area vs. its associated technologies

\begin{tabular}{|l|l|l|l|l|l|l|l|l|}
\hline \multirow{2}{*}{ Key Area } & \multicolumn{7}{|c|}{ SG Technologies } \\
\cline { 2 - 10 } & AMI & CS & DR & DMS & AO & TA & DER & ICT \\
\hline Reliability & $\sqrt{ }$ & & $\sqrt{ }$ & $\sqrt{ }$ & & $\sqrt{ }$ & $\sqrt{ }$ & $\sqrt{ }$ \\
\hline Economics & $\sqrt{ }$ & $\sqrt{ }$ & $\sqrt{ }$ & & $\sqrt{ }$ & & $\sqrt{ }$ & $\sqrt{ }$ \\
\hline Efficiency & $\sqrt{ }$ & $\sqrt{ }$ & $\sqrt{ }$ & $\sqrt{ }$ & $\sqrt{ }$ & $\sqrt{ }$ & $\sqrt{ }$ & $\sqrt{ }$ \\
\hline Environmental & $\sqrt{ }$ & $\sqrt{ }$ & $\sqrt{ }$ & $\sqrt{ }$ & $\sqrt{ }$ & $\sqrt{ }$ & $\sqrt{ }$ & $\sqrt{ }$ \\
\hline Safety & $\sqrt{ }$ & & & $\sqrt{ }$ & & & & $\sqrt{ }$ \\
\hline Security & $\sqrt{ }$ & & $\sqrt{ }$ & $\sqrt{ }$ & $\sqrt{ }$ & $\sqrt{ }$ & $\sqrt{ }$ & $\sqrt{ }$ \\
\hline
\end{tabular}


Furthermore, Figure 2 shows how SG technologies can fit in each of the system's activities and their span in relation to the electricity system [2].

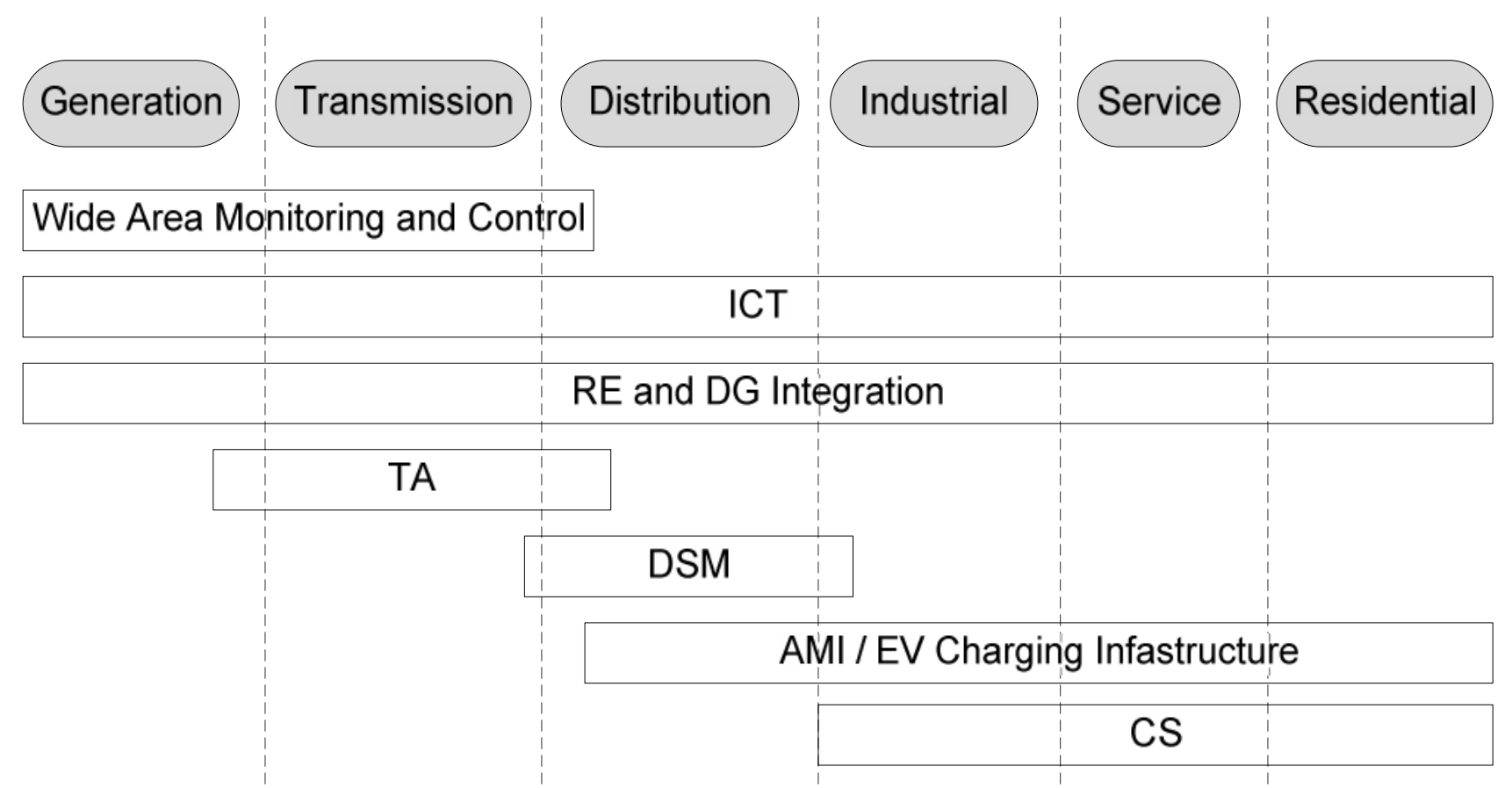

Figure (2): SG technologies span in the electric system

\section{SG Benefits:}

To reach a workable vision for the main potential beneficiaries of SGs such as utilities, consumers, and society, the SG benefit should be clear for each one of them [4].

\section{A. Utilities:}

State owned utilities have a long history of delivering electricity on a least-cost basis. They are in business to make a profit by getting an adequate return on the capital investments they make. However, investments made by utilities that reduce operational and maintenance costs can be considered as an added value. SG investments create the opportunity to get an increased adequate return on capital investments. SG investment costs are expected to be recovered through a reduction in operational costs and recovering the remaining costs from consumers. By this, it would then be likely that the utilities would be motivated to move forward, especially if their customers also support/believe in the opportunities SG is expected to bring to them. As SG becomes widely implemented with more decentralized units installed in the system and consumers responding to price signals in the new market (if applicable) the peak load will become smoother. Thus, the utilities will reduce the operation of peaking units with 
higher operating cost, and this can be translated as huge cost savings on the long run. Furthermore, under the implementation of SG, the utilities should consider the following issues [2]:

\section{$R E$ and DG integration}

Integration of RE and DG into the transmission and the distribution grids can create operational challenges from the point of view of dispatchability and controllability from the utilities. Therefore, energy storage systems can mitigate such problems by decoupling the production and delivery of electricity. Moreover, SGs can help through automation of control of generation and demand (in addition to other forms of DR) to ensure balance between supply and demand.

\section{Transmission enhancement applications}

Deployment of SG technologies on the existing transmission lines can improve efficiency and postpone the need of additional investment. High voltage DC technologies are used to connect offshore wind and solar farms to grids, with less system losses and improved system controllability. This allows efficient use of energy sources remotely from load centers. Furthermore, Dynamic Line Rating, which uses sensors to identify the current carrying capability of a section of network in real time, can optimize utilization of the transmission assets. High-temperature superconductors can significantly reduce transmission losses and enable economical fault-current limiting with higher performance, though there is a debate over the utilities' readiness of the technology.

\section{Distribution grid management}

Distribution automation can decrease the number of outages and repair time, maintain voltage level, and improve asset management. Moreover, advanced distribution automation processes real-time information from sensors and meters for fault location, automatic reconfiguration of feeders, voltage and reactive power optimization, and controls DGs.

\section{Advanced metering infrastructure}

AMI comprises the deployment of a number of technologies such as SMs that enable two-way flow of information, providing customers and utilities with data on electricity price and consumption, including the time and amount of electricity consumed.

\section{B. Consumers}

Consumers can be divided into three categories: residential (where household consumers present the majority), commercial, and industrial. Given the size of the household consumer group, it is very important to ensure that the value of SG is clear 
and convincing to them. Successfully achieving SG may well depend on how persuasive its value proposition is for this group [4]. Therefore, under the implementation of SG, the consumer-side system can be an effective tool to the SGs' success.

\section{Customer-side systems}

Customer-side systems, which are used to manage electricity consumption at the residential, commercial, and industrial levels, include energy management systems, energy storage devices, smart appliances, and DG. EE gains and peak demand reduction can be enhanced with in-home display devices, smart appliances and local storage. DR includes both manual and automated customer response, appliances and sensors that are connected to an energy management system or controlled with a signal from the utility or System Operator based on the market price. Furthermore, DR covers other areas such as AMI, and distribution management and automation.

\section{Society}

$\mathrm{SG}$ is expected to offer society with the following benefits:

- Minimizing the probability of blackout occurrences

- Reducing O\&M and capital costs due to better operating efficiencies of utilities that result in lower electricity prices for all consumers

- Improved national security by reducing the probability (and consequences) of widespread and long-term outages

- Improved environmental conditions and hence improving public health by dropping the total level of emissions through conservation and DR actions

- Reducing the number of injuries and deaths due to direct contact with grid equipment

- Improving economic growth through creation of new jobs based on demand for new products and services

- Enhancing conditions for economic development because SG can create an attractive environment for new investment

\section{Roadmap towards SG implementation:}

SG deployment has to be rationally tackled. This process can be achieved through more than one phase while addressing different areas of implementation. The findings and achievements in each phase will lead to the following one. It is probable to adjust the primarily developed mechanisms and regulations in order to smoothly shift to the coming phase. The following procedures could launch the first phase of SG implementation [5]. 


\section{Create consensus for SG deployment}

- Increase the electricity system stakeholders awareness to SGs features and benefits

- Develop and improve technological solutions in parallel with institutional structures within the electricity sector to optimize overall operations, costs and performance

\section{Set Proper Policies and regulation}

\section{Utility}

- Develop regulatory mechanisms that support increased deployment of variable generation and consumer participation in the electricity management

- Develop regulatory mechanisms and capacity building needs for enabling hurdle conventional electricity system approaches

- Develop regulatory policies to allow sharing of SG costs and benefits between generation, transmission and distribution sectors

- Tackle cyber security issues through regulation and best practice

\section{Customer}

- Codify best practice on automated DR and EE, and improve pilot projects

- Develop business models that incentivize consumers to interact with changes

- Developing policies and protection mechanisms address privacy, ownership and security of customer using information.

\section{Technology development, demonstration and deployment}

- Focus on commercial, system-wide demonstration projects addressing cost, security and sustainability issues

- Deploy SG technologies in all sectors - both in new and existing systems

- Deploy automated metering infrastructure technologies to enable demand response from all end-use sectors

- Develop and demonstrate customer-side systems

\section{Conclusions and recommendations:}

SG provides broad spectrum benefits to utilities, consumers and society as well. However, the response to the aimed transition to this market-based industry varies. Utilities are considered to be steadily proceeding, while the consumers seem to be cautious and reluctant. Nevertheless, it is definite that no single actor can provide SG; governments, private sector and customers shall work cooperatively to determine 
electricity system needs and define SG solutions. The following are recommendations for launching an SG initiative.

- Large-scale demonstrations are required in order to integrate the full SG technologies with the existing electricity infrastructure.

- Developing countries may hurdle directly to smart electricity infrastructure. This requires capacity building and targeted analysis to decide specific needs and solutions in regulation and technology.

- Regulatory models addressing system investment, prices and customer participation should be defined.

- Creating awareness and building consensus on SG worthiness.

- International cooperation is required to share experiences with pilot programs, to accelerate technology development and deployment while reducing costs for all stakeholders.

- Consumer awareness can provide the understanding, alignment, and motivation to enable active consumer participation. There should be efforts to engage the consumers hence gaining their participation, support, and enthusiasm as the process move forward.

\section{References:}

[1] KEMA, "Smart Grid developments around the globe: end of 2011 status," [Online]. Available: http://smartgridsherpa.com/wp-content/uploads/2011/12/ smart-grid-developments_end-of-2011-status.pdf

[2] "SMART GRID Information Report - September 2011". September 2011 [Online]. Available: http://www.enerweb.co.za/brochures/Smart\%20Grid\%20 Information\%20Report.pdf

[3] "Energy Transition in Africa," Africa Institute of South Africa (AISA), Dec. 2011

[4] National Energy Technology Laboratory (NETL), "Understanding the Benefits of the Smart Grid- Smart Grid Implementation Strategy," DOE/NETL-2010/1413, June 18, 2010 [Online]. Available: http://www.netl.doe.gov/smartgrid/ referenceshelf/whitepapers/06.18.2010_Understanding\%20Smart\%20Grid\%20 Benefits.pdf

[5] International Energy Agency, "IEA Smart Grids". [Online]. Available: http://www.iea.org/papers/2011/smartgrids_viewing.pdf 